\title{
Meta-Analysis on Factors Related to Children's Basic Psychological Needs
}

\author{
Eun Young Chae ${ }^{1}$, Moon Joo Cheong ${ }^{2}$ \\ Department of Child Welfare \& Studies, Sookmyung Women's University, Seoul, Korea ${ }^{1}$ \\ Department of Education, Hanyang University, Seoul, Korea ${ }^{2}$ \\ 아동의 기본심리욕구와 관련 요인에 대한 메타분석 \\ 채은영 ${ }^{1}$ 정문주 ${ }^{2}$ \\ 숙명여자대학교 아동복지학과 ${ }^{1}$ 한양대학교 교육학과 ${ }^{2}$
}

\begin{abstract}
Objective: The purpose of this study was to analyze correlation effect size between Basic Psychological Needs (BPN) and factors affecting BPN.

Methods: This research was reviewed and synthesized systematically by meta-analyse. Fifty-eight published studies between 2008 and 2016 were sampled and the effect sizes were acquired.

Results: The major findings were as follows. In general, medium correlation effect sizes were found. Competency among sub-factors of BPN showed highest effects. Parental factor was more related to BPN than school and individual factors. Parenting behavior and family psychological backgrounds were the most crucial factors in the parental factors. School adjustment was the most critical factor in the school factors. In school grade, the elementary school was more related to BPN than junior high school and high school.

Conclusion: Based on these results, we suggest a number of components for parent-education programs, and information for future research.
\end{abstract}

Keywords: basic psychological needs, meta-analysis, correlation effect size

\section{서론}

아동 발달 이론은 일반적으로 개성(individuality)과 자 율성(autonomy), 타인으로부터 분리-개별화(separationindividuation)에 대한 문제에 관심을 갖고 연구한다. 이러한 독 립, 자율성, 개인 고유성의 추구는 심리학적 탐구의 근본적 관 심사 중 하나이기도 하다(Sampson, 2000). 한편 부모는 아동의 성장과 발달 단계에 따라 자율성과 양육 및 보호에 대한 균형 을 변경할 수 있다. 이러한 균형의 변경은 생후 3 년까지인 초 기 아동기에 생겨나고, 좀 더 많은 자율성을 위해 부모와 협상

Corresponding Author: Moon Joo Cheong, Department of Education, Hanyang University, 222, Wangshimriro, Seongdong-gu, Seoul, Korea E-mail: sasayayoou@naver.com
하는 초기 청소년기에 다시 발생하게 된다(Cherney, 2010). 아 동은 성장함에 따라 다양한 문제를 개인적 영역으로서 통제하 고자 자율성을 주장하기 시작하는데, 아동의 자율성 발달은 연령 증가와 아동 자신의 노력에 의해 상당한 정도로 형성되 고 부모와의 관계에 긴장이나 갈등을 유발하기도 한다. 따라 서 부모가 아동의 자율성 욕구를 얼마나 적절히 수용하는지, 부모-자녀 관계가 얼마나 긍정적으로 형성되어 있는지가 아 동의 심리사회적 적응에 영향을 미친다(Oh, 2010). 더불어 아 동에게 또 하나의 중요한 환경인 학교에서 교사가 아동의 자 율성을 지지하는 환경을 조성하는 것은 아동의 자율성에 영향

(C)The Korean Association of Child Studies

This is an Open Access article distributed under the terms of the Creative Commons Attribution Non-Commercial License (http:// creativecommons.org/licenses/by-nc/4.0) which permits unrestricted noncommercial use, distribution, and reproduction in any medium, provided the original work is properly cited. 
을 미치며 아동의 내재동기, 심리적 안녕감이 증진되고 높은 학업 참여를 예측한다(Y. B. Heo \& Kim, 2012; H. Jang, Reeve, Ryan, \& Kim, 2009).

자기결정성 이론은 자율성을 동기의 핵심으로 보는 이론 인데, 인간을 성장과 통합을 지향하는 유기체라고 가정하고 (Ryan \& Deci, 2000) 개인의 행동은 자율성 또는 자기결정성 정도에 따라 달라진다고 하였다(Deci \& Ryan, 1985). 자기결 정성 이론은 다섯 가지의 미니 이론들로 구성된 매크로 이론 (macrotheory)으로 자기결정성에 영향을 미치는 기본심리욕 구로서 자율성, 유능성, 관계성에 대한 만족 경험을 강조한다 (Ryan \& Deci, 2002). 기본심리욕구는 인간의 보편적인 속성 이고 획득된다기보다 타고나는 필수조건으로 간주되는데, 욕 구의 충족을 통해 개인의 건설적 사회성 발달과 개인 내적인 주관적 안녕감 등을 촉진할 수 있다(Ryan \& Deci, 2002). 세 가 지 기본심리욕구를 간략히 살펴보면, 자율성 욕구는 기본심리 욕구의 필수요소로서 외부적 자원에 의해 영향을 받을 때에도 흥미와 자신이 부여한 가치에 근거하여 자신의 행동을 조절해 나가는 것을 의미한다. 자율성은 독립성과 혼동되기 쉬운데, 독립성은 외부의 영향력에 의존하지 않는다는 의미이며 의존 성에 대립되는 개념이다. 자율성은 의존성에 대립되는 개념이 아니라 타율성에 대립되는 개념으로(Ryan \& Deci, 2002), 다 른 사람의 지시와 의견에 따르면서도 자율성을 경험할 수 있 다(Ryan, 1993). 유능성 욕구는 사회적 환경과 지속적으로 상 호작용하는 과정에서 자신의 역량을 기르고 표현하는 기회를 경험하면서 자신이 유능하다고 느끼는 것을 말한다. 따라서 유능성은 행위를 통해 습득된 기술 또는 역량이라기보다 행위 를 통해 얻게 되는 자신감이라고 할 수 있다. 마지막으로 관계 성 욕구는 지역사회에 대한 소속감으로 타인을 보살피며 자신 과 타인에 의해 보살핌을 받고 있다고 느끼는 감정을 의미한 다(Ryan \& Deci, 2002).

개인이 지니고 있는 자율성, 유능성, 관계성의 기본적 욕구 를 만족시키는 것은 개인의 안녕감 증진을 위해서 필수적이다 (Ryan \& Deci, 2000). 또한 기본심리욕구의 만족이 다양한 삶 의 영역에 영향을 미치고 있음이 연구를 통해 증명되고 있다 (Jeon, 2014). 이러한 이유로 기본심리욕구의 충족과 안녕감 사이의 관련성에 대한 연구는 초기부터 활발히 이루어져 왔 고, 현재 다양한 연령층을 대상으로 한 여러 연구에서 그 관계 가 보고되고 있다(Ahn, Park, \& Jung, 2008; Noh \& Sohn, 2014). 이처럼 기본심리욕구는 아동의 안녕감 및 행복을 위한 중요한 변인으로 간주되어 연구되고 있다.

국내의 기본심리욕구와 관련된 연구는 2000 년대 중반 이
후부터 활발해졌다. 초기 연구는 주로 교육심리와 학습, 스포 츠 분야에서 기본심리욕구가 참여, 성취, 흥미, 태도, 적응, 진 로 등에 어떠한 역할을 미치는지에 대해 연구가 진행되었다. 이러한 연구 경향은 보다 다양한 분야로 기본심리욕구에 대한 관심이 확장되며 변화해가고 있는데, 건강, 대인관계, 상담 및 심리치료, 정신병리, 양육, 안녕감과 관련된 분야 뿐 아니라 경 영학과 마케팅 분야에서도 관심을 갖고 연구가 진행되기 시작 했다. 또한 연구의 대상도 아동부터 성인까지 전 생애에 걸친 다양한 연구대상을 중심으로 확장되어 아동학 분야에서도 자 기결정성과 기본심리욕구에 대한 관심을 가진 연구물들이 나 오게 되었다(J. Y. Kim, 2009; Lim, 2015). 이렇듯 기본심리욕구 에 대한 연구는 다양한 대상과 변인과의 관계에 대한 관심이 증가되었을 뿐 아니라, 기본심리욕구가 근래 점점 더 중시되 고 있는 아동의 행복이나 안녕감 등의 변인과 관련이 높아 연 구의 범위가 보다 확장되고 연구물의 수가 증가되어 왔다. 그 런데 아동의 기본심리욕구와 관련되는 것으로 연구된 변인들 은 매우 다양하고, 개별 연구에서 다룰 수 있는 변인의 수는 제 한되어 있기 때문에 각 변인이 아동의 기본심리욕구와 어느 정도 관련되는지를 비교하여 상대적 중요도를 파악하기는 어 렵다. 또한 같은 변인과 아동의 기본심리욕구의 관련성을 분 석하여 산출된 상관계수가 연구마다 다르게 나타나므로 기본 심리욕구 관련 변인의 영향력에 대해 일정한 결론을 도출하기 가 어렵다.

따라서 아동의 기본심리욕구의 충족을 위한 중요한 변인을 확인하기 위해서는 축적된 연구 결과들을 종합하여 해석하는 메타분석의 방법이 필요하다. 메타분석은 여러 연구의 계량 적 결과를 통계적으로 통합하는 방법으로(Borenstein, Hedges, Higgins, \& Rothstein, 2009) 개별 연구에 근거하여 결론을 내릴 때 수반될 수 있는 편향성을 보완하고 보다 체계적이고 객관 적으로 결론 도출의 근거를 제시하는데 유용하다. 이에 본 연 구는 기존의 선행 연구에서 보고된 아동의 기본심리욕구와 관 련된 변인들(개인, 부모, 학교 요인과 각각의 하위요인)의 관 계를 종합하여 상관관계의 효과크기(이하 효과크기와 동일) 를 분석하고자 한다. 즉 현재까지 연구된 변인들을 체계적으 로 정리하여 기본심리욕구에 대한 종합적인 이해를 돕고 변인 들의 상대적 중요도를 알아보고자 한다. 이는 앞으로의 연구 방향에 대한 아이디어를 제공하며, 아동의 기본심리욕구 충족 을 위한 발달적 이해를 통하여 부모교육 프로그램과 학교현장 에서 도움이 될 만한 객관적이고 실증적인 자료를 제공할 수 있을 것이다.

본 연구를 통해 구체적으로 밝혀보고자 하는 연구문제는 
다음과 같다.

\section{연구문제 1}

국내에서 출간된 연구물 중 기본심리욕구와 관련된 요인들 (개인, 부모, 학교)과의 전체 상관관계 효과크기는 얼마인가?

\section{연구문제 2}

기본심리욕구의 하위요인(자율성, 유능성, 관계성)과 각 관련 요인들(개인, 부모, 학교요인과 그 하위요인) 간의 상관관계 효과크기는 얼마인가?

\section{연구문제 3}

기본심리욕구와 각 관련 요인에 있어서 범주(학교급)별 상관 관계 효과크기는 어떠한가?

\section{연구문제 4}

기본심리욕구와 각 관련 요인들의 상관관계에 있어 출판연도 에 따른 상관관계 효과크기의 경향성은 어떠한가?

\section{연구방법}

\section{분석대상 논문 수집 및 선정}

본 연구의 분석대상은 2016년 4월까지 국내에서 발표된 아동 의 기본심리욕구와 관련변인에 대한 연구물을 중심으로 출간 된 학술지를 분석대상으로 선정하였다. 학술지 논문만을 분석 대상으로 선정한 것은 학술지에 게재되는 연구가 좀 더 엄격 한 심사과정을 거친다는 점에서 보다 신뢰할 수 있고 객관적 인 결과를 도출할 수 있기 때문이다(Gonseth, Guallar-Castillón,

Banegas, \& Rodríguez-Artalejo, 2004; Hyun, 2014; Paolucci, Genuis, \& Violato, 2001; Woo \& Park, 2011).

척도로는 자기결정성 이론에 근거하여 Ryan과 Deci (2002) 가 개발한 기본 심리욕구 척도 Basic Psychological Needs Scale [BPNS])와 Deci 등(2001)이 개발한 내재적 욕구 만족 척도 (Instinct Need Satisfaction Scale), 이를 토대로 하여 아동을 대상 으로 개발한 아동의 내재적 욕구 만족 척도(Children's Intrinsic Needs Satisfaction Scale [CINS]) 등을 한국어로 번안.타당화, 개 발한 척도(M. Lee \& Kim, 2008; H.-E. Lee \& Moon, 2012)를 사 용한 연구물의 것을 기본으로 하였다. 더불어 이들 척도를 근 간으로 하여 기본심리욕구 하위요인의 구성 개념을 동일하거
나 유사하게 사용하고, 연구 분야나 대상에 따라 척도를 수정, 재타당화 하여 사용한 연구물을 선정하였다.

자료 수집을 위해서 국회도서관, 과학 기술정보 통합서비 스(NDSL), 누리미디어(DB-PIA), 한국 교육학술정보원 학술 연구 정보서비스(RISS), 한국 학술정보원(KISS)의 온라인 검 색 $\mathrm{DB}$ 를 활용하여 분석대상 논문을 검색하였다. 주제어를 '기 본심리욕구'로 검색을 하여 검색된 논문을 모두 수집하였으 며, 기본심리욕구 외에 '자율성, 유능성, 관계성 욕구', '기본심 리욕구와 내·외재적 동기' 등의 검색어를 포함하여 수집하였 다. 자료 수집 기간은 2 주 소요되었고, 자료 검색 결과 학술지 논문 334편, 석.박사 학위 논문 1,227 편, 단행본 2,581 편, 공개 강의 자료 3 편, 연구 보고서 15 편을 모두 포함하여 총 4,160 편 이 검색되었다. 이 중 연구 보고서 15 편, 공개강의 자료 3 편, 단행본 2,581 편, 석.박사 학위 논문 1,227 편을 제외 학술지 논 문 총 334편을 연구대상으로 선정하였다. 이렇게 선정된 334 편의 논문 중 기본심리욕구와 관련이 있는 논문만을 선별하 기 위해 1 차 분석을 실시하였다. 1 차 분석 결과, 직·간접적으 로 기본심리욕구와 그 하위요인인 자율성, 유능성, 관계성에 서 벗어난 논문 98편(우울, 무기력, 분노, 창의성, 외상 후 스트 레스 등관 관련한 심리정서요인), 아동 대상 논문이 아닌 경우 121 편, 연구자나 기관의 요청으로 원문 공개가 안 되었거나 원문을 구할 수 없는 경우 5편, 질적 연구 12 편, 경향성 연구 5 편을 제외하였다.

이후 1 차 분석을 통해 선정된 93 편의 논문에 대해 2 차 분석 을 실시하였다, 기본 심리욕구 관련 상관관계 값이 제공되지 않은 논문 25 편, 상관관계 값을 계산하는데 필요한 평균 표준 편차, $t, F, p$ 등의 수리적 정보가 제시되어 있지 않은 논문 10 편을 제외하였다. 2 차 분석 결과 총 58 편의 학술지 논문을 추 출하여 메타분석을 실시하였다. 논문 선정 기준은 Table 1 과 Figure 1의 PRISMA flowchart와 같다.

\section{분석대상 논문의 처리 및 분석}

\section{자료코딩 및 분류기준}

본 연구에서 기본심리욕구와 관련된 요인들의 효과크기를 분 석하기 위해 Ryan과 Deci (2002)의 자기결정성 이론 중 하나인 기본심리욕구 이론에 토대를 두고 국내에서 척도 번안 및 타 당화, 혹은 개발 및 타당화 한 척도를 사용한 연구들을 분석 대 상으로 참고하여 코딩하였다(S. Han \& Shin, 2009; M. Lee \& $\mathrm{Kim}, 2008$; Park \& Kim, 2008). 기본심리욕구 관련한 내·외적 
Table 1

The Studies Analytical Criteria Factors and Framework

\begin{tabular}{ll}
\hline \multicolumn{1}{c}{ Factor } & \multicolumn{1}{c}{ Standard contents } \\
\hline Independent mediator & Basic psychological need (BPN): Autonomy; competence; relatedness \\
Statistics data & All sorts of figures, such as mean; standard deviation; $t$ values; $F$ values; calculating effect size \\
Moderator & Years; school grade (elementary, junior high school, high school) \\
Related factors & Individual factors; parental factors; school factors \\
\hline
\end{tabular}

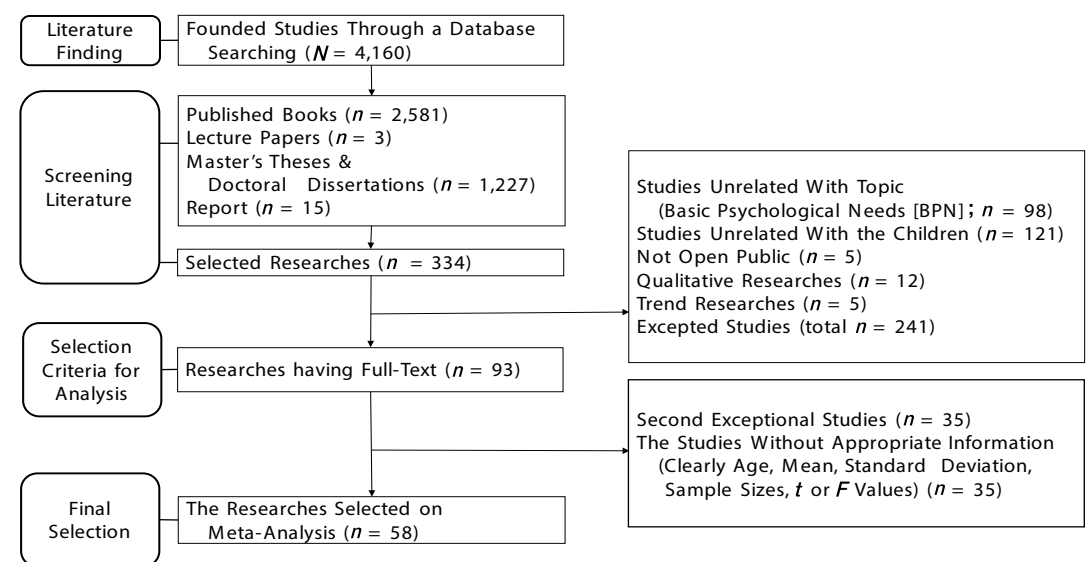

Figure 1. PRISMA flowchart.

요인과 범주 요인(categorical variables)은 Moon과 Kang (2008) 의 연구의 분류를 기반으로 하여 개인, 부모, 학교 요인으로 분 류하여 코딩하였다. 분석 시 범주요인은 출판연도, 학교 급(초, 중, 고)으로 분류하여 코딩하였다. 코딩 표에는 논문의 기본 정 보(저자, 출판연도, 표본 수, 상관관계 값을 포함한 통계 수치, 학교 급)와 각 관련 요인들의 하위 요인들을 입력하였다.

자료를 입력하는 과정에서 다양한 관련요인으로 인해 연구 자료를 유목화 하는데 있어서 2 인의 연구자들 간의 불일치가 발생하였는데, 이 경우 공동 저자인 두 명의 연구자가 함께 의 견을 교환한 후 아동상담 전공 교수 1 명과 교육학 박사 1 명의 자문을 받아 의견을 취합하여 연구자간 코딩 불일치 문제를 해결하려 하였다.

연구자간 불일치가 나타난 부분은 첫째, 기본 심리욕구의 하위요인을 구분하여 각 변인별 상관관계 효과크기를 볼 것인 지, 기본심리욕구 전체를 단일 요인으로 하여 효과크기 분석 을 할 것인지에 대한 부분에서 불일치가 존재했다. 둘째, 본 연 구의 대상인 아동의 연령을 범주화 시킬 것인지, 원자료를 사 용할 것인지에 대한 불일치가 존재하였다. 이차적으로는 기본 심리욕구 관련 요인들의 다양성으로 인하여, 이들의 상관관계 효과크기를 분석할 때 정보의 손실의 문제가 발생하였기 때문
에 이러한 정보의 손실을 최소화하기 위하여 요인 간 의미가 유사하거나, 정적과 부적으로 표현된 요인들은 기존의 기본심 리욕구 관련 요인들의 연구(Moon \& Kang, 2008)를 기반으로 범주화하기로 합의하였다. 이에 개인 요인은 동기, 목표, 스트 레스, 운동관련, 자아관련, 정서, 조절, 중독, 진로, 학업, 행동 으로, 부모 요인은 가정심리환경, 부모 정서 표현, 양육 행동, 부모의 자율성 지지, 부모의 진로 선택으로 유목화 하였다. 학 교 요인은 교사, 또래, 학교생활로 유목화 한 후 교사는 애착, 자율성지지, 통제로, 또래는 관계와 환경으로, 학교생활은 적 응과 참여로 유목화 하였다. 이 연구의 분류체계는 Table 2에 제시한 바와 같다.

\section{자료 분석 절차 및 효과크기 계산}

본 연구에서는 효과크기 및 동질성 검증 등의 자료 분석을 위 해 MS Excel 2013을 사용하여 코딩하였고, 메타 분석을 위한 통 계 프로그램인 CMA (Comprehensive Meta-Analysis) Version 2 (Biostat, Englewood, NJ) 프로그램을 이용하였다. 자료 분석 절 차는 전체 출판 편향 검증, 동질성 검증 및 전체 상관관계 효과 크기 분석, 개인, 부모, 학교요인에 따른 동질성 검증 및 아동 
Table 2

Categorization of Factors Related to Basic Psychological Needs

\begin{tabular}{|c|c|}
\hline Related factor & Area \\
\hline \multicolumn{2}{|l|}{ Individual factors } \\
\hline \multirow[t]{4}{*}{ Motivation } & SDT \\
\hline & Flow \\
\hline & Interesting \\
\hline & Inner motive \\
\hline \multirow[t]{2}{*}{ Goal } & Achievement goal \\
\hline & Life goal \\
\hline \multirow[t]{3}{*}{ Stress } & Stress management \\
\hline & External stress \\
\hline & Internal stress \\
\hline \multicolumn{2}{|l|}{ Athletics } \\
\hline \multirow[t]{2}{*}{ Self } & Identity \\
\hline & Self-respect \\
\hline \multicolumn{2}{|l|}{ Affect } \\
\hline \multirow[t]{2}{*}{ Regulation } & Self-regulation \\
\hline & Life-regulation \\
\hline \multirow[t]{3}{*}{ Addiction } & Internet addiction \\
\hline & Smart phone addiction \\
\hline & Game addiction \\
\hline \multirow[t]{2}{*}{ Career } & Career planning \\
\hline & Career decision \\
\hline \multicolumn{2}{|l|}{ Scholastic achievements } \\
\hline \multicolumn{2}{|l|}{ Behavior } \\
\hline \multicolumn{2}{|l|}{ Parental factors } \\
\hline \multicolumn{2}{|l|}{$\begin{array}{l}\text { Family psychological } \\
\text { backgrounds } \\
\text { Parents' emotional expression }\end{array}$} \\
\hline \multicolumn{2}{|l|}{ Parenting behavior } \\
\hline \multicolumn{2}{|l|}{ Autonomy support } \\
\hline \multicolumn{2}{|l|}{ Parents' career choice } \\
\hline \multicolumn{2}{|l|}{ School factors } \\
\hline \multirow[t]{3}{*}{ Teacher } & Attachment \\
\hline & Autonomy support \\
\hline & Control \\
\hline \multirow[t]{2}{*}{ Peer } & Relationship \\
\hline & Atmosphere \\
\hline \multirow[t]{2}{*}{ School life } & Adjustment \\
\hline & Participation \\
\hline
\end{tabular}

Note. $\mathrm{BPN}=$ basic psychological need.

의 기본심리욕구와의 상관관계 효과 크기, 요인 간의 조절효 과 분석과 연도별 메타회귀분석의 과정을 거쳤다.

분석의 세부적인 과정은 다음과 같다. 첫째, 출판편향 (publication bias)을 검증하였다. 일명 책상서랍의 문제(file drawer problem)가 야기되는 경우로서, 연구자가 부정적인 연 구결과를 보고하지 않거나 혹은 과소추정하며 긍정적인 연
구 결과만을 보고하는 경향으로 인해 메타분석에서 표집의 대 표성을 확보하지 못하여 출판편향의 문제가 발생하게 된다 (Rosenthal \& Rosnow, 1991). 이러한 출판편향의 문제는 메타 분석의 대상이 되는 표본이 모집단의 특성을 제대로 반영하 지 못한다고 간주되므로 도출된 분석결과의 신뢰성과 타당성 에 문제가 발생한다(Hwang, 2014). 그러므로 본격적인 분석에 앞서 메타분석에 활용된 표본의 편향성을 살펴볼 필요가 있다 (Rothstein, Sutton, \& Borenstein, 2005; Stern \& Egger, 2001). 출 판 편향을 확인하기 위한 완벽한 하나의 방법은 존재하지 않 으므로(Rothstein et al., 2005), 본 연구에서는 funnel plot을 통 하여 수집된 논문들이 출판편향이 있는지 확인하고, 추정치 가감법(trim and fill)을 상호보완적으로 활용하여 분석대상이 된 논문의 편향성 여부를 분석하였다.

둘째, 동질성 검증 및 이질성 분석을 실시하였다. 동질성 검 증은 모든 효과 크기들이 동일한 모집단의 효과크기를 추정 하고 있는가의 여부를 검정하는 것을 의미한다(Hwang, 2014). 본 연구에서도 각각의 효과크기들이 동일한 모집단의 효과 크기를 추정하고 있는가에 대해 살펴보기 위해 동질성 검증 의 통계량 $Q$ 값을 산출하였다. 그러나 $Q$ 값은 각 연구의 모집 단의 효과크기들이 모두 같다는 귀무가설만을 검증할 뿐이므 로(Hwang, 2014) 효과크기의 동질성을 넘어선 초과분산을 산 출하기 위해서 $I^{2}$ 값을 산출하였다. $p$ 값이 . 10 보다 작고, $I^{2}$ 값이 $50 \%$ 이상이면 각 프로그램의 효과크기들은 상당한 정도의 이 질성이 있다고 판단할 수 있다(Higgins \& Green, 2011).

셋째, 기본심리욕구와 관련된 요인들과의 전체 상관관계 효과크기(이하 효과크기) 검증을 실시하였다. 전체 효과크기 검증 시에는 동일한 주제의 연구들이라 할지라도 서로 일치하 지 않은 척도로 분석한 연구물도 있기 때문에, 그 결과들을 종 합하기 위해서는 동일 크기로 바꾸어 주는 표준화 과정이 필 요하다. 이러한 표준화된 척도를 메타분석에서는 효과크기 (effect size)라 한다(Hwang, 2014; B.-S. Jang \& Shin, 2011). 하지 만 본 연구에서는 효과크기를 그대로 보고하지 않고 Fisher's $Z$ 값으로 전환하였다(Wilson, Lipsey, \& Derzon, 2003). 이는 상관 계수의 분산이 상관계수의 크기에 민감하기 때문에 상관계수 가 큰 경우 정적인 편의(positive bias)가 발생할 수 있으므로 $r$ 값 보다는 표준화된 값인 Fisher's $Z$ 로 변환하여 계산한 후 보고한 다(Borenstein et al., 2009).

넷째, 기본심리욕구와 관련변인의 하위 범주인 개인, 부모, 학교요인에 따른 동질성 검증, 기본심리욕구와의 효과크기, 학교 급(초, 중, 고)에 따른 상관관계 효과크기를 분석하였다. 마지막으로 기본심리욕구 전체, 각각의 기본심리욕구의 하위 
요인들의 출판연도별 상관관계 효과크기의 경향성을 예측해 보기 위해 meta-회귀분석을 실시하였다.

\section{연구 결과}

\section{출판편향 검증}

최종 선정된 58 편의 논문(효과크기 사례 수 $=1,176$ )에 대한 출 판편향의 분석을 실시하였다. 본 연구에서는 funnel plot을 통 하여 수집된 논문들의 출판편향을 살펴보고 추정치 가감법 방 법을 활용하여 상호보완적으로 표본의 편향성 여부를 분석하 였다. Figure 2에서 보는 바와 같이 funnel plot은 어느 정도 좌 우대칭을 이루고 있다. 또한 상호보완적인 방법인 추정치 가 감법으로 일종의 민감도 분석을 해본 결과 Table 3 과 같이 조
율된 연구물의 보정 값과 관찰 값이 같아서 출판편향이 존재 한다고 보기 어려웠다.

\section{기본심리욕구 전체 변인간의 상관관계 효과크 기 및 효과의 동질성 검증}

본 연구에서 선정한 58 편의 연구물에서 나온 1,176 개의 효과 크기로부터 계산된 전체 효과크기를 산출 한 결과는 Table 4 와 같다. 유의 수준 .05에서 동질성 검정을 실시한 결과 $Q$ 값은 $22,060.935(p<.01)$ 로 귀무가설이 기각되어 이질적인 것으로 판단하여 무선효과(random effect) 모형을 적용하였다(Higgins \& Green, 2011; Hwang, 2014). 또한 총 분산 대비 비율을 나타 내는 $I^{2}$ 의 값 역시 94.674로, 50보다 크므로 상당한 이질성을 가지고 있는 것으로 나타났다. 위의 결과를 통하여 각 연구가

Table 3

Trim-and-Fill Test Result

\begin{tabular}{lcccc}
\hline & Studies trimmed & ESzr & $95 \%$ CI & $Q$ \\
\hline Observed & & .394 & {$[.382, .405]$} & \\
Adjusted & 0 & .394 & {$[.382, .405]$} & $6,959.63975$ \\
\hline
\end{tabular}

Note. $\mathrm{ES} z r=$ effect size; $\mathrm{CI}=$ confidence interval; $Q=$ homogeneity statistic.
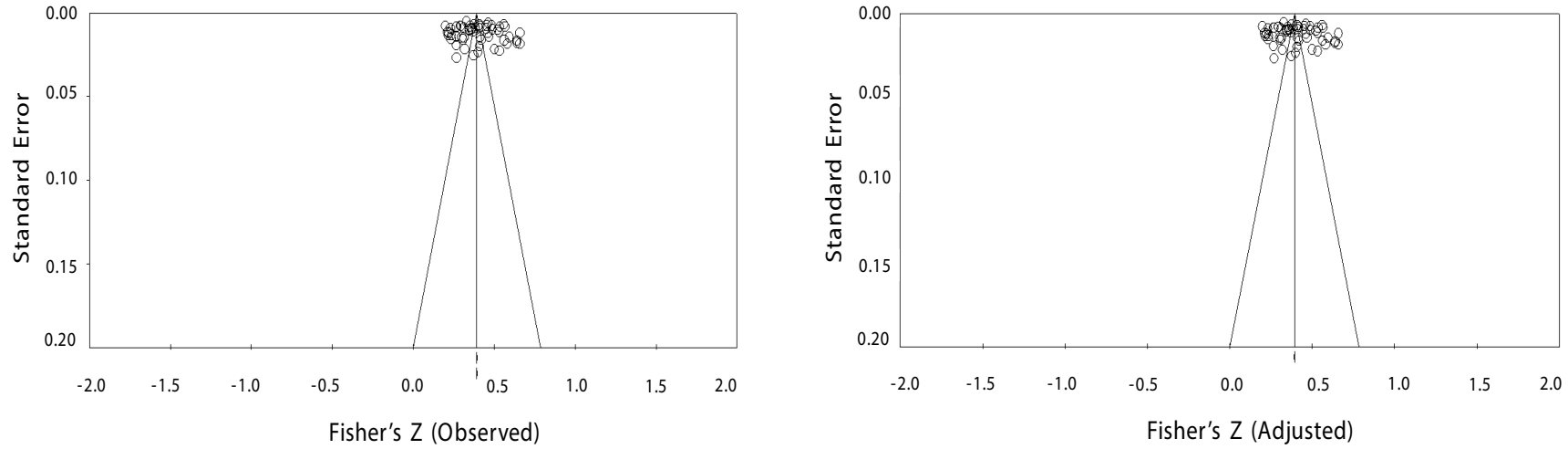

Figure 2. Funnel plot.

Table 4

Validation of Homogeneous and the Correlation Effect Size of Basic Psychological Needs

\begin{tabular}{|c|c|c|c|c|c|c|c|c|c|c|}
\hline & \multirow[b]{2}{*}{$n$} & \multirow[b]{2}{*}{$k$} & \multicolumn{4}{|c|}{ Heterogeneity } & \multicolumn{4}{|c|}{ Random effect model } \\
\hline & & & $Q(d f)$ & $p$ & $P^{2}$ & $S E$ & $\mathrm{ES} z r$ & $S E$ & $95 \% \mathrm{CI}$ & $p$ \\
\hline Total & 58 & 1,176 & $22,060.935$ & .000 & 94.674 & .001 & .394 & .006 & {$[.382, .405]$} & .000 \\
\hline
\end{tabular}

Note. $n=$ the number of the researches; $k=$ the number of effect sizes; $Q=$ homogeneity statistic; $S E=$ standard error; ES = effect sizes; $\mathrm{CI}=$ confidence interval. 
각각 다른 연구자들에 의해 다른 방식으로 연구되었기 때문 에 모집단 효과크기 추정치가 동일하다고 볼 수 없으므로 본 논문에서는 무선효과모형을 제시하였다. 따라서 무선효과 모 형으로 분석한 결과 전체 상관관계 효과크기는 .394로 중간정 도의 상관관계 효과크기였다(Cohen, 1977). 행동 과학 분야에 있어 표준화된 상관관계 효과크기를 해석하는데 있어서 제안 된 기준은 .10-.30은 작은 효과크기, .30-.50은 중간 효과크기, .50 이상의 값은 큰 효과크기이다(Cohen, 1977; Hwang, 2014).

\section{기본심리욕구가 사용된 변인 종류에 따른 상 관관계 효과크기}

기본심리욕구의 변인 종류에 따른 상관관계 효과크기를 분석 하였다. 기본심리욕구를 매개변수로 사용한 경우 $(n=452)$ 가 가장 많았고, 독립변인 $(n=435)$, 종속변인 $(n=183)$, 상관 변인 $(n=78)$, 조절 변인 $(n=28)$ 의 순으로 더 많이 사용되었다. 효 과크기는 조절 변인 $(\mathrm{ES}=.443)$, 독립변인 $(\mathrm{ES}=.421)$, 매개변인 $(\mathrm{ES}=.402)$, 상관변인 $(\mathrm{ES}=.35)$, 종속 변인 $(\mathrm{ES}=.32)$ 의 순서였 으며, 사용한 변인에 따른 효과크기는 통계적으로 유의하게 차이가 있었다 $\left(Q_{\mathrm{b}}=36.730[4], p<.01\right)$.

\section{기본심리욕구 하위요인(자율성, 유능성, 관계 성)과 전체 변인 간의 상관관계 효과크기}

기본심리욕구의 하위요인과 전체 변인간의 상관관계 효과크 기를 분석한 결과는 아래 Table 6과 같다. 하위요인인 자율성, 유능성, 관계성인 각 하위요인의 집단 간 차이는 통계적으로 유의하였다 $\left(Q_{\mathrm{b}}=10.271, p<.01\right)$. 분석 결과 유능성(.425), 관 계성(.377), 자율성(.368) 순으로 $95 \%$ 신뢰구간에서 전체 상관 관계 변인들과 통계적으로 유의미한 효과 크기를 갖는 것으로 나타났다(Cohen, 1977).

\section{기본심리욕구 관련 각 개별 요인(개인, 부모, 학교)의 효과크기}

기본심리욕구와 각 관련 요인인 개인, 부모, 학교의 효과크기 를 분석한 결과는 아래 Table 7과 같다. 세 개의 각 요인의 집단 간 차이는 통계적으로 유의하였으며 $\left(Q_{b}=7.817, p<.05\right)$, 분석 결과 부모요인(.421), 학교요인(.414), 개인요인(.384) 순으로 $95 \%$ 신뢰구간에서 통계적으로 모두 유의미한 효과 크기를 갖 는 것으로 나타났다(Cohen, 1977).

Table 5

Correlation Effects Size According to Variable Types of Basic Psychological Needs

\begin{tabular}{lcccccc}
\hline \multicolumn{1}{c}{ BPN } & $k$ & $\mathrm{ES}_{z r}$ & $S E$ & $95 \% \mathrm{CI}$ & $p$ & $Q_{\mathrm{b}}$ \\
\hline Independent & $435(36.9 \%)$ & .421 & .010 & {$[.401, .441]$} & .000 & $36.730(4)^{* *}$ \\
Mediate & $452(38.4 \%)$ & .402 & .009 & {$[.385, .419]$} & .000 & .000 \\
Correlate & $78(6.6 \%)$ & .350 & .020 & {$[.311, .389]$} & .000 & .000 \\
Moderate & $28(2.3 \%)$ & .443 & .047 & .015 & {$[.290, .350]$} & $.534]$ \\
Dependent & $183(15.5 \%)$ & .320 & .000 & \\
\hline
\end{tabular}

Note. $\mathrm{BPN}=$ basic psychological need; $k=$ the number of effect sizes; $\mathrm{ES}_{z r}=$ effect sizes; $S E=$ standard error; $\mathrm{CI}=$ confidence interval; $Q_{\mathrm{b}}=$ between groups homogeneity.

${ }^{* *} p<.01$.

Table 6

Correlation Effect Size Between Basic Psychological Needs (Sub-Factors) and Related Factors

\begin{tabular}{lcccccc}
\hline \multicolumn{1}{c}{ Sub-Factor } & $k$ & $\mathrm{ES}_{z r}$ & $S E$ & $95 \% \mathrm{CI}$ & $p$ & $Q_{\mathrm{b}}$ \\
\hline Autonomy & 346 & .368 & .011 & {$[.347, .388]$} & .000 & $10.271(2)^{* *}$ \\
Competency & 346 & .425 & .011 & {$[.392, .437]$} & .000 & .000 \\
Relatedness & 353 & .377 & .010 & {$[.357, .396]$} & & \\
\hline
\end{tabular}

Note. $k=$ the number of effect sizes; $\mathrm{ES}_{z r}=$ effect sizes; $S E=$ standard error; $\mathrm{CI}=$ confidence interval; $Q_{\mathrm{b}}=$ between groups homogeneity. ${ }^{* *} p<.01$. 
기본심리욕구 하위 요인(자율성, 관계성, 유능 성)과 전체 관련 요인(개인, 부모, 학교) 간의 상관관계 효과크기

기본심리욕구의 하위요인인 자율성, 유능성, 관계성과 관련된 전체 요인인 개인, 부모, 학교와의 상관관계 효과크기를 분석 한 결과는 아래 Table 8 과 같다. 첫 번째 각 기본심리욕구의 하 위요인인 자율성과 개인, 부모, 학교 요인 간의 집단 간 차이 는 통계적으로 유의하지 않았으나, 자율성과 각각의 부모요인 (.422), 학교요인(.376), 개인요인(.359)의 순으로 $95 \%$ 신뢰구 간에서 상관관계 효과크기는 통계적으로 유의하였다(Cohen, 1977). 두 번째 기본심리욕구의 하위요인인 유능성과 개인, 부 모, 학교 요인 간의 집단 간 차이는 통계적으로 유의하지 않았 으나, 유능성과 각각의 학교요인(.418), 개인요인(.414), 부모 요인(.409)의 순으로 $95 \%$ 신뢰구간에서 상관관계 효과크기 는 통계적으로 유의하였다(Cohen, 1977). 세 번째 기본심리욕 구의 하위요인인 관계성과 개인, 부모, 학교 요인 간의 집단 간 차이는 통계적으로 유의하였으며 $\left(Q_{\mathrm{b}}=20.398, p<.01\right)$, 관계
성과 각각의 부모요인(.447), 학교요인(.433), 개인요인(.349) 의 순으로 $95 \%$ 신뢰구간에서 상관관계 효과크기는 통계적으 로 유의하였다(Cohen, 1977).

\section{기본심리욕구와 개인관련 요인 간의 상관관계 효과크기}

기본심리욕구와 개인요인의 집단 차이는 상관관계 효과크기 는 통계적으로 유의미하였다 $\left(Q_{\mathrm{w}}=302.540, p<.01, d f=784, p\right.$ <.01). 이에 무선 효과를 사용하여 기본심리욕구와 개인요인 의 하위요인과 영역별 효과크기를 분석하였다. 개인요인과 기 본심리욕구간의 상관관계는 $\mathrm{ES}_{z r}=.337$ 로 중간효과크기이다 (Cohen, 1977). 기본심리욕구와 개인요인의 하위요인별 상관 관계 효과크기 결과는 학업(.585), 자아(.575), 정서(.537), 운동 (.398), 조절(.353), 동기(.315), 진로(.313), 행동(.307), 스트레 스(.286), 목표(.277), 중독(.215) 순으로 나타났다.

기본심리욕구의 하위요인인 자율성과 개인요인의 하위요 인간의 상관관계 효과크기를 분석한 결과 자율성과 개인의

Table 7

Correlation Effect Size Between Basic Psychological Needs and Related Factors

\begin{tabular}{lrccccc}
\hline \multicolumn{1}{c}{ Factor } & $k$ & $\mathrm{ES}_{z r}$ & $S E$ & $95 \% \mathrm{CI}$ & $p$ & $Q_{\mathrm{b}}$ \\
\hline Individual & 804 & .384 & .007 & {$[.369, .398]$} & .000 & $7.817(2)^{*}$ \\
Parental & 93 & .421 & .017 & {$[.388, .454]$} & .000 & .000 \\
School & 279 & .414 & .011 & {$[.393, .435]$} & \\
\hline
\end{tabular}

Note. $k=$ the number of effect sizes; $\mathrm{ES}_{z r}=$ effect sizes; $S E=$ standard error; $\mathrm{CI}=$ confidence interval; $Q_{\mathrm{b}}=$ between groups homogeneity. ${ }^{*} p<.05$.

Table 8

Correlation Effect Size Between Basic Psychological Needs (Sub-Factors) and Related Factors

\begin{tabular}{|c|c|c|c|c|c|c|c|}
\hline $\mathrm{BPN}$ & Factor & $k$ & $\mathrm{ES}_{z r}$ & $S E$ & $95 \% \mathrm{CI}$ & $p$ & $Q_{\mathrm{b}}$ \\
\hline \multirow[t]{2}{*}{ Autonomy } & Individual & 240 & .359 & .013 & {$[.332, .385]$} & .000 & $2.798(2)$ \\
\hline & Parental & 26 & .422 & .037 & {$[.350, .495]$} & .000 & \\
\hline \multirow[t]{2}{*}{ Competency } & Individual & 243 & .414 & .015 & {$[.385, .443]$} & .000 & $.065(2)$ \\
\hline & Parental & 26 & .409 & .035 & {$[.341, .477]$} & .000 & \\
\hline \multirow[t]{3}{*}{ Relatedness } & Individual & 242 & .349 & .011 & {$[.327, .371]$} & .000 & $20.398(2)^{* *}$ \\
\hline & Parental & 29 & .447 & .025 & {$[.398, .496]$} & .000 & \\
\hline & School & 82 & .433 & .022 & {$[.389, .476]$} & .000 & \\
\hline
\end{tabular}

Note. $k=$ the number of effect sizes; $\mathrm{ES}_{z r}=$ effect sizes; $S E=$ standard error; $\mathrm{CI}=$ confidence interval; $Q_{\mathrm{b}}=$ between groups homogeneity. ${ }^{* *} p<.01$. 
하위요인의 상관관계 효과크기는 정서(.465), 운동(.402), 조 절(.366), 동기(.352), 행동(.275), 목표(.164) 순으로 나타났으 며, 각 집단 간 상관관계 차이는 통계적으로 유의하였다 $\left(Q_{\mathrm{b}}=\right.$ $65.870, p<.01)$. 기본심리욕구의 하위요인인 유능성과 개인요 인의 하위요인 간의 상관관계 효과크기를 분석한 결과 유능성 과 개인의 하위요인의 상관관계 효과크기는 정서(.547), 운동 (.441), 조절(.370), 목표(.334), 동기(.317), 행동(.268), 스트레 스(.227) 순으로 나타났으며, 각 집단 간 상관관계 차이는 통계 적으로 유의하였다 $\left(Q_{\mathrm{b}}=75.279, p<.01\right)$. 기본심리욕구의 하 위요인인 관계성과 개인요인의 하위요인 간의 상관관계 효과
크기를 분석한 결과 관계성과 개인요인의 하위요인 간 상관관 계 효과크기는 정서(.501), 행동(.382), 운동(.346), 목표(.314), 조절(.309), 동기(.280) 순으로 나타났으며, 각 집단 간 상관관 계 차이는 통계적으로 유의하였다 $\left(Q_{b}=36.608, p<.01\right)$. 그 자 세한 결과는 다음 Table 9에 제시하였다.

\section{기본심리욕구와 부모관련 요인 간의 상관관계 효과크기}

무선 효과 모델(random effects model)을 사용하여 기본심리욕

Table 9

Correlation Effect Size Between Basic Psychological Needs (Sub-Factors) and Individual Factors

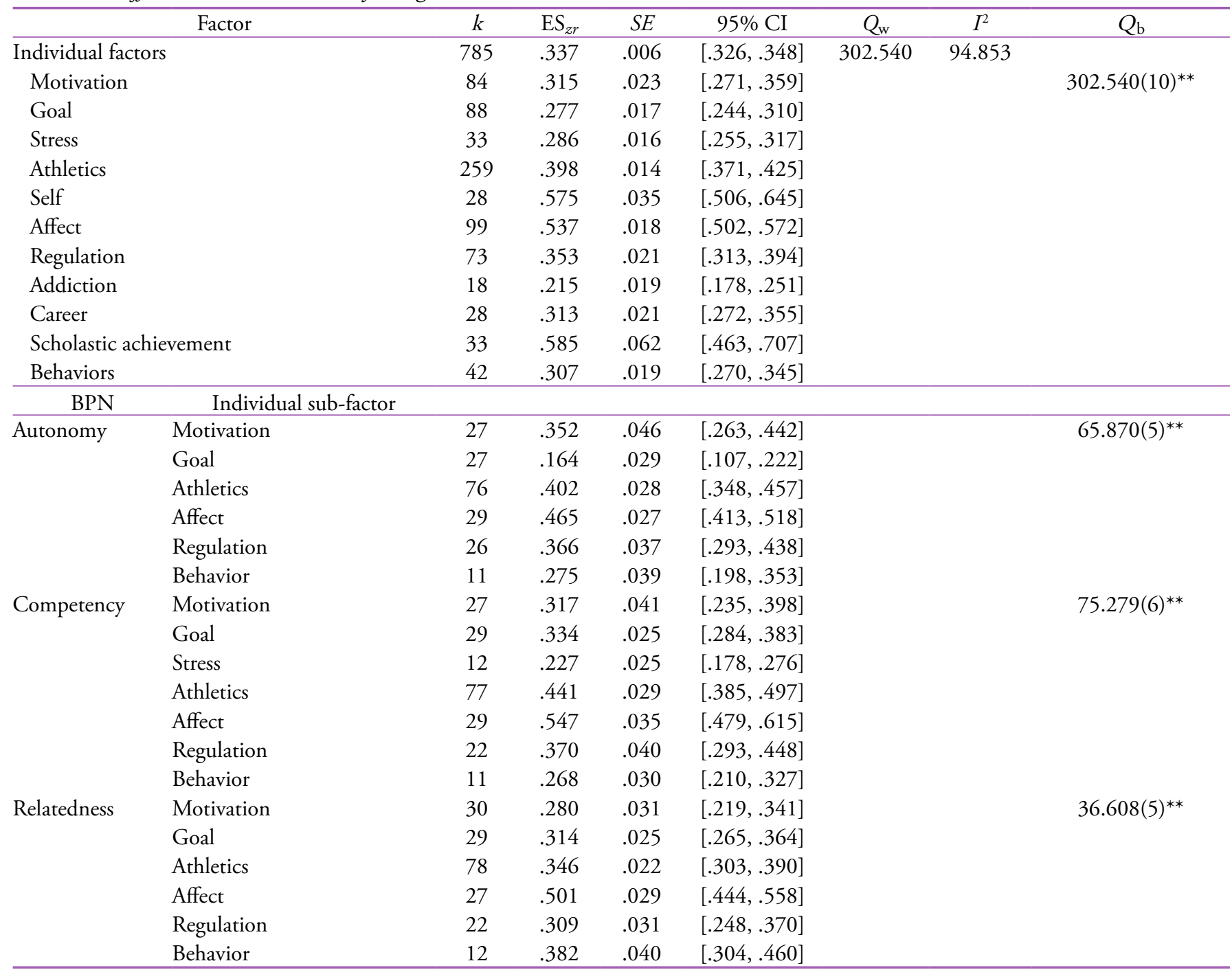

Note. $k$ = the number of effect sizes; $\mathrm{ES}_{z r}=$ effect sizes; $S E=$ standard error; $\mathrm{CI}=$ confidence interval; $Q_{\mathrm{w}}=$ within domain homogeneity; $I^{2}=$ percentage of heterogeneity due to domain differences; $Q_{b}=$ between groups homogeneity.

${ }^{* *} p<.01$. 
구와 부모 하위 요인의 집단 간 차이를 분석하여 각 요인별 상 관관계 효과크기를 산출하였다. 이에 부모요인의 하위요인과 기본심리욕구 전체와의 상관관계 효과크기 통계적으로 유의 하였고 $\left(Q_{\mathrm{w}}=554.873, d f=72, p<.01\right)$, 부모 하위요인과 기본 심리욕구의 상관관계 효과크기는 $\left(\mathrm{ES}_{z r}=.398\right)$ 로 중간 효과크 기였다(Cohen, 1977).

부모 요인만을 연구대상으로 기본심리욕구와 부모 하위 요인과의 상관관계 효과크기를 분석한 결과, 부모 양육행동 (.583), 가정심리환경(.539), 부모의 자율성지지(.399), 부모 정 서표현(.383), 부모진로 선택(.339) 순으로 효과크기를 보였 으며, 각 하위요인들 간의 효과크기 차이는 통계적으로 유의 하였다 $\left(Q_{\mathrm{b}}=32.927, p<.01\right)$. 또한 기본심리욕구의 하위요인 인 자율성, 유능성, 관계성에 따른 분석은 사례 수가 10 개미만 (Hwang, 2014)이었으나 사례수가 부족한 변인들의 분석을 통 해 중요한 정보를 제공받을 수 있을 것으로 판단하여 분석을 실시하였다. 기본심리욕구의 하위요인인 자율성과 부모 하위
요인의 상관관계 효과크기를 분석해 본 결과 양육행동(.647), 자율성지지(.549), 부모 정서표현(.461), 부모 진로 선택(.388), 가정심리환경(.202) 순이었고 각 상관관계 효과크기는 통계 적으로 유의하였으나 집단 간 차이는 통계적으로 유의하지 않았다. 기본심리욕구의 하위요인인 유능성과 부모하위요인 의 상관관계 효과크기를 분석해 본 결과 자율성지지(.606), 부 모 정서표현(.604), 가정심리환경(.509), 부모 진로선택(.477), 양육행동(.355)의 순이었고 각 상관관계 효과크기는 통계적 으로 유의하였으며 집단간 차이는 통계적으로 유의하지 않았 다. 마지막으로 기본심리욕구의 하위요인인 관계성과 부모 하위요인의 상관관계 효과크기를 분석해 본 결과 부모 정서 표현(.521), 양육행동(.469), 부모 진로선택(.453), 자율성지지 (.404), 가정심리환경(.383)의 순이었고 각 상관관계 효과크기 는 통계적으로 유의하였으나 집단 간 차이는 통계적으로 유의 하지 않았다(Table 10).

Table 10

Correlation Effect Size Between Basic Psychological Needs (Sub-Factors) and Parental Factors

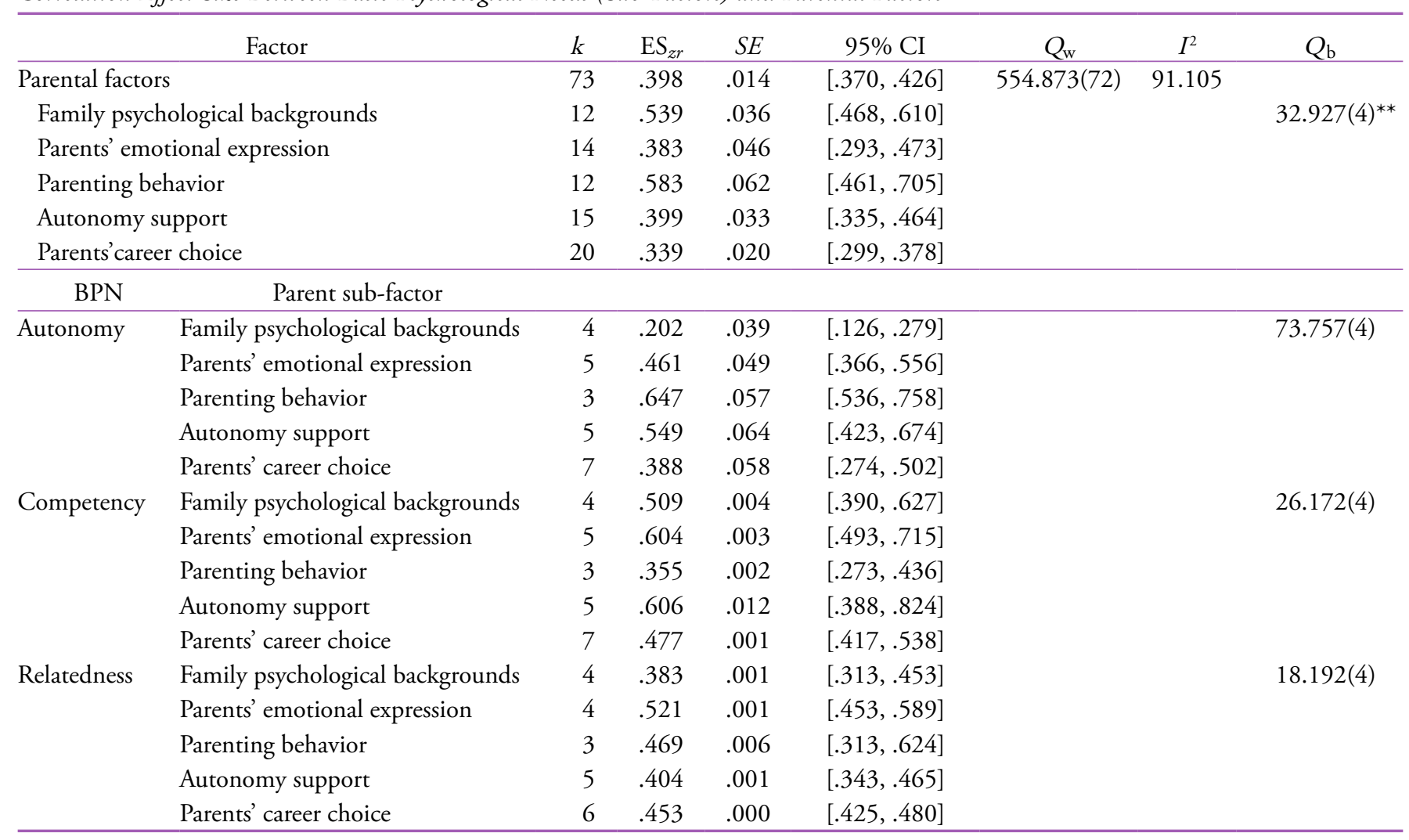

Note. $k$ = the number of effect sizes; $\mathrm{ES}_{z r}=$ effect sizes; $S E=$ standard error; $\mathrm{CI}=$ confidence interval; $Q_{\mathrm{w}}=$ within domain homogeneity; $I^{2}=$ percentage of heterogeneity due to domain differences; $Q \mathrm{~b}=$ between groups homogeneity.

${ }^{* *} p<.01$. 


\section{기본심리욕구와 학교관련 요인 간의 상관관계 효과크기}

무선효과 모델(random effects model)을 사용하여 기본 심리욕 구와 관련된 요인 중 학교요인의 하위 구조의 효과크기를 분 석하였다. 학교요인의 효과크기는 통계적으로 유의한 효과 크기를 나타냈고 $\left(Q_{\mathrm{w}}=4,805.936(258), d f=256, p<.01\right)$, 기본 심리욕구와 학교 요인 간의 상관관계 전체효과 크기는 $\mathrm{ES}_{z r}=$ .399로 중간 정도의 효과 크기였다.

기본심리욕구와 학교하위 요인 간의 상관관계 효과크기 결과는 학교(.512), 또래(.329), 교사(.307) 순으로 나타났으며, 각 하위요인 간의 효과 차이도 통계적으로 유의하였다 $\left(Q_{\mathrm{b}}=\right.$ $124.339(2), p<.01)$. 또한 학교요인의 하위요인의 각 요인 간 분석에 있어서 학교의 경우 학교 적응(.519), 학교 참여(.498), 또래 요인에 있어서 또래관계(.400), 또래와의 분위기(.261), 또한 학교 내 교사의 영역별 하위요인에 있어서는 교사의 자
율(.410), 교사통제(.286), 교사 애착(학생, 학교; .275)의 순으 로 상관관계 효과크기를 나타냈으며, 각 집단 간 차이가 통 계적으로 유의함을 나타냈다 $\left(Q_{\mathrm{b}}=188.301(2), p<.01\right)$. 또한 기본심리욕구의 하위요인인 자율성과 학교하위요인의 상관 관계 효과크기를 분석해 본 결과 또래 관계(.847), 교사 관련 (.376), 학교 적응(.270) 순으로 각 상관관계 효과크기는 통계 적으로 유의하였으나 집단 간 차이는 통계적으로 유의하지 않 았다. 기본심리욕구의 하위요인인 유능성과 학교하위요인의 상관관계 효과크기를 분석해 본 결과 또래 관계(.778), 교사 관 련(.435), 학교 적응(.369)순으로 각 상관관계 효과크기는 통 계적으로 유의하였으며 집단간 차이는 통계적으로 유의하지 않았다. 마지막으로 기본심리욕구의 하위요인인 관계성과 학 교하위요인의 상관관계 효과크기를 분석해 본 결과 또래관계 (.590), 학교 적응(.423), 교사 관련(.419)의 순으로 각 상관관계 효과크기는 통계적으로 유의하였으나 집단간 차이는 통계적 으로 유의하지 않았다(Table 11).

Table 11

Correlation Effect Size Between Basic Psychological Needs (Sub-Factors) and School Factors

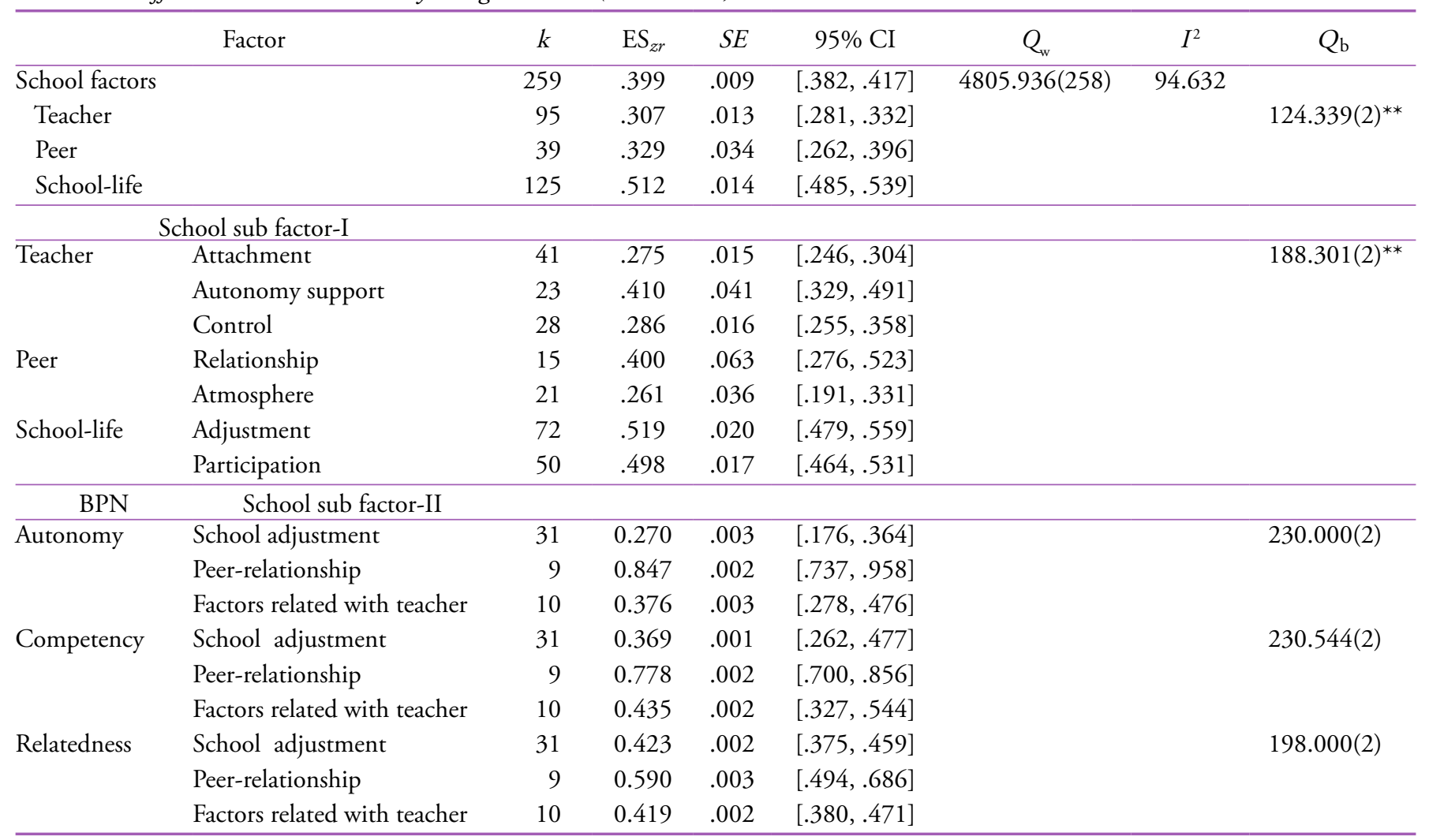

Note. $Q_{\mathrm{b}}=$ the difference verification between groups; $\mathrm{ES}=$ effect sizes; $S E=$ standard error; $\mathrm{CI}=$ confidence interval; $k=$ the number of effect sizes.

${ }^{* *} p<.01$. 


\section{기본심리욕구와 학교급 별 상관관계 효과크기}

전체 기본심리욕구 관련 요인과 학교급의 효과크기를 분석

해 본 결과, 각각의 급별 차이는 통계적으로 유의하였으며 $\left(Q_{b}\right.$
= 27.194(2), $p<.01)$, 초등학생(.437), 중학생(.377), 고등학생 (.346) 순으로 나타났다.

기본심리욕구의 하위요인인 자율성과 학교급을 상관관계 효과크기를 분석해 본 결과 초등학생(.409), 고등학생(.372),

Table 12

Correlation Effect Size Between Basic Psychological Needs (Sub-Factors) and School Levels

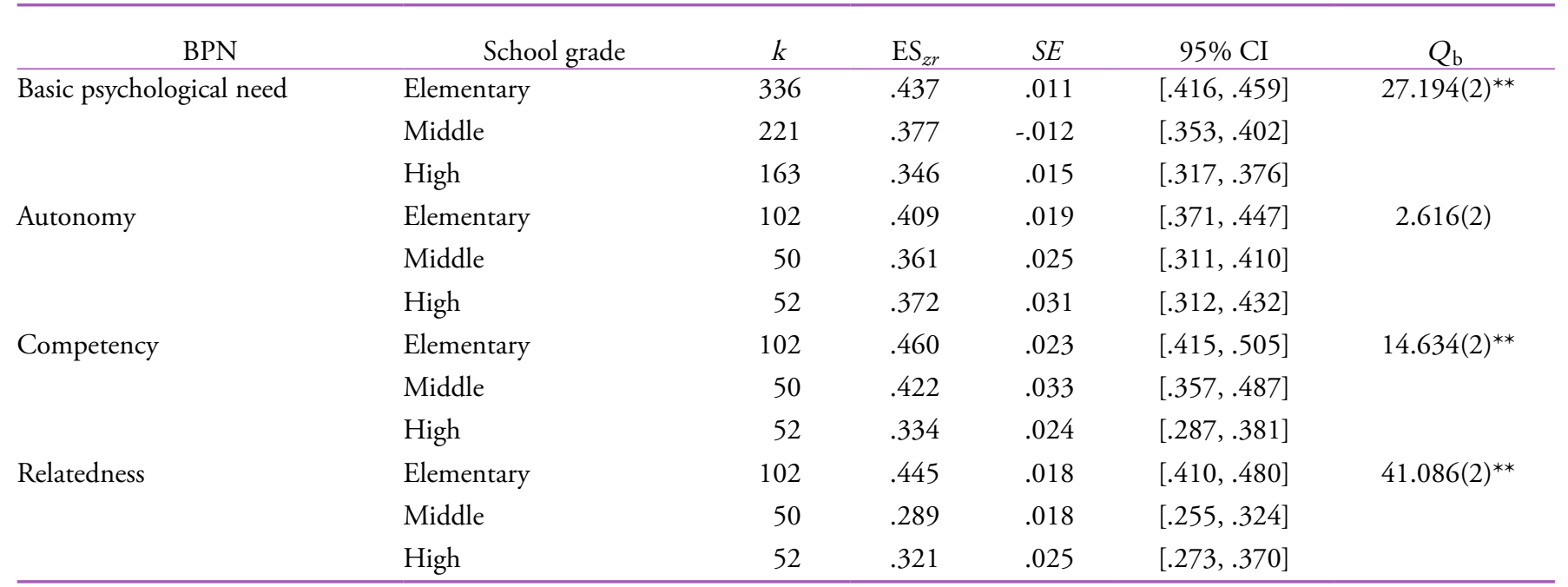

Note. $k=$ the number of effect sizes; $\mathrm{ES}_{z r}=$ effect sizes; $S E=$ standard error; $\mathrm{CI}=$ confidence interval; $Q_{\mathrm{b}}=$ between groups homogeneity. ${ }^{* *} p<.01$.

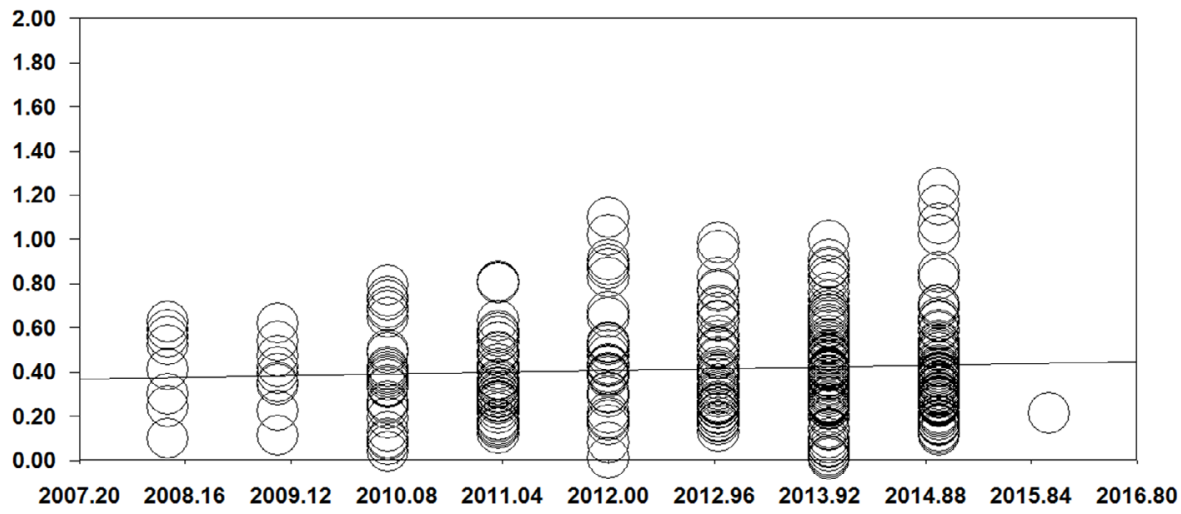

Figure 3. Regression analysis of basic psychological needs by years.

Table 13

Regression Analysis of Basic Psychological Needs by Years

\begin{tabular}{lrrrrrr}
\hline & Value & \multicolumn{1}{c}{$S E$} & $-95 \%$ CI & +95\% CI & \multicolumn{1}{c}{$\tau^{2}$} \\
\hline$\beta$ & .00691 & .00309 & .00036 & .01296 & 2.23693 \\
Intercept & -13.50854 & 6.21494 & -25.68960 & -1.32748 & -2.17356 \\
\hline
\end{tabular}


중학생(.361)의 순으로 각 상관관계 효과크기는 통계적으로 유의하였으나 집단 간 차이는 통계적으로 유의하지 않았다 $\left(Q_{\mathrm{b}}=2.616\right)$. 기본심리욕구의 하위요인인 유능성과 학교 급을 상관관계 효과크기를 분석해 본 결과 초등학생(.460), 중학생 (.422), 고등학생(.334)의 순으로 각 상관관계 효과크기는 통계 적으로 유의하였으며 집단 간 차이 역시 통계적으로 유의하였 다 $\left(Q_{\mathrm{b}}=14.634, p<.01\right)$. 기본심리욕구의 하위요인인 관계성 과 학교 급을 상관관계 효과크기를 분석해 본 결과 초등학생 (.445), 고등학생(.321), 중학생(.289)의 순으로 각 상관관계 효 과크기는 통계적으로 유의하였으나 집단 간 차이는 통계적으 로 유의하지 않았다 $\left(Q_{\mathrm{b}}=41.086\right)$. 그 결과는 다음의 Table 12 과 같다.

\section{출판 연도별 기본심리욕구 관련 전체 효과 크 기 회귀 분석}

학술지를 연도별로 분류 한 후 각 학술지의 출판 연도를 연속 변수로 코딩한 후 회귀 분석한 결과, 2007년 연구와 2015년 연 구의 효과크기의 변화는 출판 연도의 변화에 따라 기본 심리 욕구의 상관관계 효과 크기 변화가 크지 않은 것을 확인할 수 있다(Figure 3, Table 13). 또한 기울기 계수를 확인한 결과 통계 적으로 유의하지 않았다.
기본심리욕구의 하위요인인 자율성, 유능성, 관계성 요인 각각과 연구물에서 출판연도를 연속변수로 코딩하여 상관관 계의 연도별 효과크기의 경향을 알아보기 위하여 메타 회귀분 석을 실시하였다. 그 결과 자율성, 유능성은 출판 연도의 변화 에 따라 상관관계 효과 크기 변화가 크지 않았고, 기울기 계수 를 확인한 결과 통계적으로 유의하지 않았다. 반면 관계성의 경우, 출판 연도의 변화에 따라 관계성과 각 관련 변인간의 상 관관계 효과 크기 변화가 유의하게 커지는 것을 확인할 수 있 었다. 기울기 계수를 확인한 결과 역시 통계적으로 유의하였 다 $(\beta=.00492, p<.01)$. 자세한 결과는 Table 14 , Figure 4 에 나 타나있다.

\section{논의 및 결론}

본 연구는 기본심리욕구 연구가 국내에서 시작된 2008년부터 2016년 4월까지 국내 학술지에 게재된 아동을 대상으로 한 58 편의 논문을 대상으로 메타분석을 실시하였다. 메타분석을 통 해 다양한 선행 연구에서 발표된 아동의 기본심리욕구에 영향 을 미치는 주요 변인들을 확인하고 주요 변인들과 기본심리욕 구 간 관계의 종합 평균효과크기를 알아보며 아동의 기본심리 욕구와 관련된 변인을 확인하고 관련변인들의 영향력을 체계

Table 14

Regression Analysis of Basic Psychological Needs (Relatedness) by Years

\begin{tabular}{lccrrrr}
\hline & & & & & \\
$\tau^{2}$ & & \\
$\beta$ & Value & $S E$ & $-95 \%$ CI & $+95 \%$ CI & .79200 & .04552 \\
Intercept & $.00492^{* *}$ & .00622 & -.00726 & .01711 & -.75886 & \\
\hline
\end{tabular}

${ }^{* *} p<.01$.

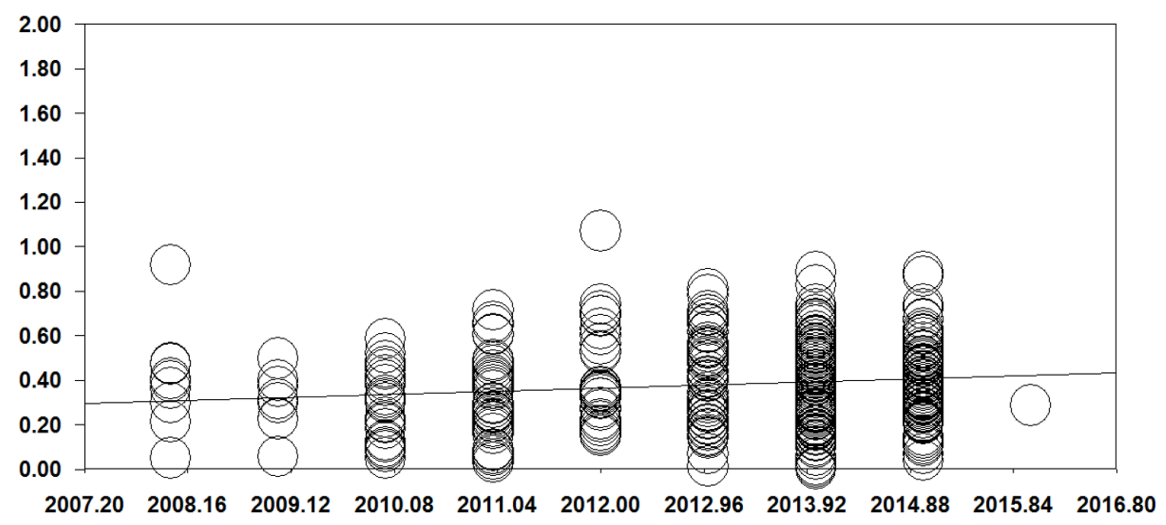

Figure 4. Regression analysis of basic psychological needs (relatedness) by years. 
화하기 위해 실시되었다.

메타분석 결과, 기본심리욕구와 관련 변인들의 상관관계 효과크기는 중간 정도의 효과크기를 나타냈으며, 기본심리욕 구의 하위요인과 전체 변인간의 상관관계 효과크기는 유능성, 관계성, 자율성의 순으로 나타났다. 이는 아동의 경우 다른 변 수들에 가장 영향을 미치는 기본심리욕구의 하위 요인은 유능 성이라는 것인데, 유능성이 삶의 만족이나 학습, 학교 규칙, 교 사 관계 등과 가장 상관이 높다는 연구(E.-J. Heo \& Oh, 2014; Jeon, 2014)와 관계성 및 유능성 충족이 아동기의 사회적 적응 에 더 중요한 영향력이 있는 것으로 보고한 S.-Y. Lee (2013)의 연구를 지지하는 결과이다. 반면 자율성의 경우 다른 변인들 과의 관계가 가장 적은 것으로 나타났는데, 이는 자율성을 기 본심리욕구 중 가장 핵심으로 보고 자율성이 보장되어야 유능 성을 발휘하는 것으로 자율성의 중요성을 강조한 Ryan과 Deci (2002)의 의견과는 다소 차이가 있는 결과이다. 이는 한국 사 회 및 문화적 특징으로 해석되기도 하고 아동기 심리사회적 발달 과업의 성취 과정 중 자아에 대한 유능감의 충족의 중요 성으로 해석되기도 한다(S.-Y. Han \& Chang, 2015; E.-J. Heo \& Oh, 2014; Jeon, 2014). 더불어 처음 기본심리욕구 척도를 번안 하여 타당화한 M. Lee와 Kim (2008)의 연구에서 한국 학생들 의 기본심리욕구 만족 측정 척도는 자율성과 유능성을 나누기 보다 하나의 척도로 구성하는 것이 보다 적절할 수도 있다고 제언한 것을 고려하여 추후 연구에서 척도 구성에 대해 신중 한 판단을 할 필요가 있음을 시사한다.

아동의 기본심리욕구와 관련 변인의 상관관계 효과크기는 부모 요인, 학교 요인, 개인 요인의 순이었다. 하위요인에 따른 분석에서는 자율성의 경우 부모 요인과 가장 큰 효과크기를 나타냈고, 관계성의 경우 부모와 학교 변인이 개인변인에 비 해 상대적으로 큰 효과크기를 나타냈다. 유능성의 경우는 학 교, 개인, 부모 요인이 모두 비슷한 중간정도의 효과크기를 나 타냈다. 이는 부모 요인과 아동이 많은 시간을 보내는 학교 요 인이 개인 요인보다 아동의 기본심리욕구에 영향을 많이 미치 고 있는 것으로 해석할 수 있다. 이는 부모, 교사 및 사회가 아 동의 기본심리욕구인 자율성, 유능성, 관계성 충족의 중요성 을 인식하고 이를 만족시키기 위한 환경을 조성하기 위해 노 력해야 한다는 점을 시사한다.

구체적으로 살펴보면 첫째, 아동의 기본심리욕구와 개인요 인의 하위요인별 상관관계 효과크기는 학업, 자아, 정서 요인 에서 .5 이상의 높은 상관관계 효과크기(Cohen, 1977)를 나타 냈다. 자율성의 경우 정서, 운동과 비교적 높은 효과크기를 나 타냈고, 유능성의 경우 정서, 운동에서 비교적 높은 효과크기
를 나타냈다. 관계성의 경우 정서에서 높은 상관관계 효과크 기를 나타냈다. 기본심리욕구 관련 초기 연구에서부터 연구되 어온 주제인 학업 관련 변인은 기본심리욕구와 높은 효과크 기를 나타내고 있으며 하위요인인 자율성, 유능성, 관계성은 모두 정서 요인과 높은 효과크기를 보이고 있다. 이는 기본심 리욕구의 충족에 대체적으로 높은 자존감, 자기 효능감이 영 향을 미치며, 기본심리욕구의 충족이 과제 관여, 불안과 전반 적 자존감을 예측한다는 결과(Chirkov \& Ryan, 2001)와 부분 적으로 일치하는 결과로 보인다. 둘째, 부모관련 요인은 양육 행동, 가정심리환경 요인이 기본심리욕구와 5 이상의 큰 효과 크기를 나타냈다. 이는 자율성, 유능성, 관계성 모두에서 가족 문제 해결, 가족생활 시간 공유, 가족 규칙 등의 가정환경의 영 향을 많이 받는다는 Jeon, Shin과 Yoo (2011)의 연구결과를 지 지하는 결과이다. 이는 아동복지법 상 아동에 속하고 주로 청 소년이라고 명명되는 중·고등학생의 경우도 여전히 가족이나 부모와의 관계는 중요한 요인이란 것(M. J. Kim \& Ko, 2016) 을 다시한번 강조하는 결과이다. 또한 자녀의 우울이나 공격 성, 문제 행동에 영향을 줄 수 있고(Markey, Ericksen, \& Tinsley, 2001), 부모의 양육 행위가 부적절하게 이루어지면 자녀의 자 기결정성 발달을 저해하여 학교생활 및 학업 성취에 부정적 인 영향을 줄 수 있으므로(Shin, Jin, \& Kim, 2010), 아동의 기 본심리욕구 충족을 위한 부모의 양육행동은 아동의 여러 발달 에 있어 중요한 변인이 된다는 점을 시사한다. 셋째, 기본심리 욕구와 학교 요인 간의 상관관계 전체 효과 크기는 중간 정도 의 효과 크기였고, 기본심리욕구와 학교 하위 요인 간의 상관 관계 효과크기 결과는 학교 요인이 교사, 또래 요인에 비해 높 은 효과크기를 나타냈다. 학교요인의 각 하위요인 간 분석에 있어서 학교 적응, 학교 참여가 보다 큰 효과크기를 나타냈다. 이는 교사가 지각하는 학생의 유능감(Deci \& Ryan, 1990), 학 교에 대한 긍정적 태도, 학업 수행 등이 기본심리욕구에 영향 을 준다는 연구결과(Y. B. Heo \& Kim, 2012)를 지지하는 것이 다. 더불어 높은 또래 동조는 관계성과 관련이 있다는 결과와 관계성이 학교생활 적응과 교사관계, 또래관계와 상관이 높은 것으로 나타난 연구 결과들(Jeon, 2014; Jeon et al., 2011)은 학 습 이외의 학교 요인과 관계성이 관련이 있음을 예측할 수 있 게 한다. 넷째, 학교급 별 분석에서는 초등학생, 중학생, 고등 학생 순으로 기본심리욕구와 더 높은 효과크기를 나타냈다. 기본심리욕구의 하위요인인 자율성과 관계성의 경우, 초등학 생, 고등학생, 중학생의 순으로 학교급 별 효과크기를 나타냈 으나, 유능성의 경우는 초등학생, 중학생, 고등학생 순으로 나 타났다. 이는 한국 교육 실정에서 성적과 입시라는 변수가 아 
동의 유능성에 많은 영향을 주고 있다는 것을 보여주는 결과 라고 생각된다. 이는 과도한 입시경쟁으로 인해 학년이 올라 갈수록 기본심리욕구를 충족시킬 수 있는 경험의 기회가 적어 지기 때문이라고 $(\mathrm{Lim}, 2015)$ 보이며, 아동의 기본심리욕구 충 족을 위한 아동 상담 및 부모교육 프로그램 실시에 있어서 학 교급에 따른 아동의 특성을 반영해야 할 필요가 있음을 시사 하는 것이다. 마지막으로 출판연도에 따른 상관관계 효과크기 를 분석한 결과, 기본심리욕구는 지속적으로 다른 변인들과 중간 정도의 효과크기를 나타내고 있고, 하위 요인 중 관계성 만이 최근의 논문일수록 각 요인과의 상관관계가 높아지는 결 과를 나타냈다. 이는 최근으로 올수록 관계성이 다른 변인들 과의 관련성이 높아지고 있다는 것을 의미하는 것이다. 사실 관계성 욕구에 만족에 대한 결과는 선행 연구들에서 확실히 드러나지 않은 경향이 있는데, 최근의 연구들에서는 관계성 욕구 만족의 중요성이 점차 확인되고 있다(Y. B. Heo \& Kim, 2012). 이는 앞선 결과들에서 관계성이 대부분 자율성, 유능성 과는 다른 양상을 보이고 관계성 욕구의 충족은 내적동기 증 진보다는 타인과의 상호작용을 통해 그 자체로서 개인에게 만 족감을 주기 때문에 긍정적인 행동을 증가시킨다는 연구결과 (Ryan \& Deci, 2002)에서도 알 수 있듯이, 아동에게 있어서 관 계성은 자율성, 유능성과 유기적인 관계가 아니라 독립된 변 인으로 인식되고 있을 가능성을 시사한다. 또한 아동의 기본 심리욕구와 관계성 욕구를 충족시킬 수 있는 경험을 가정과 학교에서 많이 제공해야한다는 점을 시사하며 이는 아동의 전 반적인 발달에도 긍정적인 영향을 미칠 것으로 생각된다.

본 연구는 국내에서 수행된 아동의 기본심리욕구에 대한 연구들을 통합하고 앞으로의 연구 방향을 제시하며, 아동의 기본심리욕구 충족을 위한 아동 발달적 이해를 돕는 자료를 제공했다는데 의의가 있다. 연구물을 누락 없이 검색하여 찾 으려 했으나 누락된 논문이 존재할 수 있고 선정된 논문만으 로 종합적 분석을 하는데 한계점이 있을 수 있다는 제한점이 존재한다. 이에 후속 연구에서는 석.박사 학위논문이나 국외 의 자료를 포함하여 아동의 기본심리욕구 관련 변인을 종합하 여 제시하거나, 국내와 국외의 문화적인 차이를 고려하여 비 교·분석할 필요가 있다. 또한 더 많은 연구물이 축적된 후에 본 연구에서 개별 효과크기 수의 부족으로 제외된 변인들을 포함시켜 탐색한다면 새로운 결과들을 도출할 수 있을 것으로 보인다. 마지막으로 현재까지 아동의 기본심리욕구와 관련한 종합적인 개관 논문(review paper)은 부족한 실정인데, 향후 비 교 분석을 통해 다양한 자료를 제시할 수 있도록 본 연구와 유 사한 방식의 연구가 수행되길 기대한다.

\section{Conflict of Interest}

No potential conflict of interest relevant to this article was reported.

\section{References}

\section{In English}

Borenstein, M., Hedges, V., Higgins, P., \& Rothstein, H. (2009). Introduction to meta-analysis. West Sussex, UK: John Wiley \& Sons, Ltd. doi:10.1002/9780470743386

Cherney, I. D. (2010). Mothers', fathers', and their children's perceptions and reasoning about nurturance and self-determination rights. International Journal of Children's Rights, 18, 79-99. doi:10.11 63/092755609X12482670820520

Chirkov, I., \& Ryan, R. M. (2001). Parent and teacher autonomysupport in Russian and U.S. adolescent: Common effects on well-being and academic motivation. Journal of Cross Cultural Psychology, 32(5), 618-635. doi:10.1177/0022022101032005 006

Cohen, J. (1977). Statistical Power Analysis for the Behavioral Sciences. New York: Academic Press.

Comprehensive Meta-Analysis (Version 2) [Computer software]. Retrieved from https://www.meta-analysis.com/

Deci, E. L., \& Ryan, R. M. (1985). The empirical exploration of intrinsic motivational processes. In L. Berkowitz (Ed.), Advances in experimental social psychology (Vol. 38, pp. 39-80). New York: Academic Press. doi:10.1016/S00652601(08)60130-6

Deci, E. L., \& Ryan, R. M. (1990). A Motivational approach to self: Integration in personality. In R. Dienstbier (Ed.), Nebraska symposium on motivation: Perspectives on motivation (Vol. 38, pp. 237-288). Lincoln, NE: University of Nebraska Press.

Gonseth, J., Guallar-Castillón, P., Banegas, J. R., \& RodríguezArtalejo, F. (2004). The effectiveness of disease management programmes in reducing hospital re-admission in older patients with heart failure: A systematic review and metaanalysis of published reports. European Heart Journal, 25(18), 1570-1595. doi:10.1016/j.ehj.2004.04.022

Higgins, J. P. T., \& Green, S. (2011). Cochrane handbook for systematic reviews of interventions. Haymarket, London: The Cochrane Collaboration.

Jang, H., Reeve, J., Ryan, R. M., \& Kim, A. (2009). Can selfdetermination theory explain what underlies the productive, satisfying learning experiences of collectivistically oriented korean students? Journal of Educational Psychology, 101(3), 
644-661. doi:10.1037/a0014241

Markey, C. N., Ericksen, A. J., \& Tinsley, B. J. (2001). Personality and family determinants of preadolescents' participation in health-compromising and health-promoting behaviors. Adolescent and Family Health, 2(2), 83-90.

Paolucci, E. O., Genuis, M. L., \& Violato, C. (2001). A metaanalysis of the published research on the effects of child sexual abuse. The Journal of Psychology, 135(1), 17-36. doi:10.1080/00223980109603677

Rosenthal, R., \& Rosnow, L. (1991). Essentials of behavioral research: Methods and data analysis (2nd ed.). New York: McGraw-Hill.

Rothstein, H. R., Sutton, A. J., \& Borenstein, M. (2005). Publication bias in meta-analysis. In H. R. Rothtein, A. J. Sutton, \& M. Borenstein (Eds.), Publication bias in metaanalysis: Prevention, assessment and adjustments (pp 13-29). doi: $10.1002 / 0470870168$

Ryan, R. M. (1993). Agency and organization: Intrinsic motivation, autonomy and the self in psychological development. In J. Jacobs (Ed.), Nebraska symposium on motivation: Developmental perspectives on motivation (Vol. 40, pp. 1-56). Lincoln, NE: University of Nebraska Press.

Ryan, R. M., \& Deci, E. L. (2000). Self-determination theory and the facilitation of intrinsic motivation, social development, and well-being. American Psychologist, 55(1), 68-78. doi:10.1037/0003-066x.55.1.68

Ryan, R. M., \& Deci, E. L. (2002). Overview of self-determination theory: An organismic dialectical perspective. In E. L. Deci \& R. M. Ryan (Eds.), Handbook of self-determination research (pp. 3-33). Rochester, NY: Rochester University Press.

Sampson, E. E. (2000). Reinterpreting individualism and collectivism: Their religious roots and monologic versus dialogic person-other relationship. American Psychologist, 55(12), 1425-1432. doi:10.1037/0003-066X.55.12.1425

Stern, J. A. C., \& Egger, M. (2001). Funnel plots for detecting bias in meta-analysis: Guidelines on choice of axis. Journal of Clinical Epidemiology, 54(10), 1046-1055. doi:10.1016/ S0895-4356(01)00377-8

Wilson, S. J., Lipsey, M. W., \& Derzon, J. H. (2003). The effects of school-based intervention programs on aggressive behavior: A meta-analysis. Journal of Consulting and Clinical Psychology, 71(1), 136-149. doi:10.1037/0022006X.71.1.136

\section{In Korean}

Ahn, D., Park, K., \& Jung, J. (2008). The relationship between autonomy support, basic needs, and psychological wellbeing. Korean Journal of Youth Studies, 15(5), 315-338.
Retrieved from http://www.riss.kr/link?id=A75113581

Han, S., \& Shin, H. (2009). Effects of basic psychological needs satisfaction in parent-child relationships on subjective wellbeing in University students. Korean Journal of Counseling and Psychotherapy, 21(2), 439-464. Retrieved from http:// www.dbpia.co.kr/Article/NODE06369726

Han, S.-Y., \& Chang, S.-J. (2015). The mediating effects of children's basic psychological needs satisfaction in the relationship between parental psychological control and children's aggression. Korea Journal of Counseling, 16(4), 459-479. Retrieved from http://www.riss.kr/link?id=A100825601

Heo, E.-J., \& Oh, I.-S. (2014). The relationship between psychological needs and hope on adolescents' school adjustment. Journal of Educational Studies, 45(3), 137-165. doi:10.15854/ jes.2014.09.45.3.137

Heo, Y. B., \& Kim, A. (2012). The mediating effects of basic psychological needs in the relationship between students' perception of their teacher's autonomy support and selfdirected learning. The Korean Journal of Educational Psychology, 26(4), 1075-1096. Retrieved from http://www.riss.kr/ link?id=A99570157

Hwang, S. D. (2014). The Meta-Analysis comprehension, Easy to Know. Seoul: Hakjisa.

Hyun, Y.-S. (2014). A meta-research of reliability and validity of self-directed learning scales. Journal of Lifelong Education, 20(1), 33-62. Retrieved from http://www.riss.kr/ link?id=A100055569

Jang, B.-S., \& Shin, I.-S. (2011). The effect of self-regulated program on elementary school students: A meta-analysis. The Journal of Curriculum Studies, 29(4), 187-211. Retrieved from http://www.riss.kr/link?id=A87001132

Jeon, S. H. (2014). Validation of the Korean adolescent's basic psychological need scale. Journal of Adolescent Welfare, 16(1), 31-64. Retrieved from http://www.riss.kr/link?id=A99961288

Jeon, S. H., Shin, M., \& Yoo, M. S. (2011). A study on factors affecting life satisfaction and wellbeing in youth. Korean Journal of Youth Studies, 18(1), 275-296. Retrieved from http://www.riss.kr/link?id=A82503311

Kim, J. Y. (2009). A study on the parents' verbal control modes and the self-determination motivation of children (Master's thesis). Retrieved from http://www.riss.kr/link?id=T11577786

Kim, M. J., \& Ko, J. (2016). Family cohesion and happiness of youth: mediating effects of a positive attitude. Korean Journal of Child Studies, 37(1), 83-94. doi:10.5723/ kjcs.2016.37.1.83

Lee, H.-E., \& Moon, S.-B. (2012). A structural analysis of schoolaged children's well-being and its related variables. Journal of Korean Home Management Association, 30(3), 45-57. doi:10.7466/JKHMA.2012.30.3.045

Lee, M., \& Kim, A. (2008). Development and construct validation 
of the basic psychological needs scale for Korean adolescents: Based on the self-determination theory. The Korean Journal of Social and Personality Psychology, 22(4), 157-174. Retrieved form http://www.riss.kr/link?id=A100629694

Lee, S.-Y. (2013). The mediating effects of the basic psychological needs in the relationships between the perceived parenting attitudes and the school adjustment of the secondary school students (Doctoral dissertation). Retrieved from http://www.riss.kr/ link?id=T13054391

Lim, S. (2015). Differential association of motives and goal contents with psychological well-being: Regression mixture modeling approach (Doctoral dissertation). Retrieved from http:// www.riss.kr/link?id=T13847576

Moon, E. S., \& Kang, S. H. (2008). A structural analysis of the social and motivational variables related to high school students' psychological well-being. The Korean Journal of Educational Psychology, 22(1), 1-15. Retrieved from http:// www.riss.kr/link?id=A75417699

Noh, H., \& Sohn, W. (2014). Relationships of primary school students' intrinsic and extrinsic life goals with their basic psychological needs and well-being. The Korean Journal of School Psychology, 11(2), 355-375. Retrieved from http:// www.dbpia.co.kr/Article/NODE06372450

Oh, H. S. (2010). Effects of factors on school achievement and self-directedness development of middle school students: Focused on mothers' social support. Korean Journal of School Psychology, 7(2), 269-293. Retrieved from http:.//
www.dbpia.co.kr/Article/NODE06372359

Park, J.-G., \& Kim, K.-H. (2008). Development and validation of the basic psychological needs scale for athletes. Korean Journal of Sport Psychology, 19(4), 53-72. Retrieved from http://www.riss.kr/link?id=A75726935

Shin, J., Jin, S., \& Kim, Y. (2010). The influence of perceived parental academic support, achievement expectation and daily control on children's self-determination motivation according to their academic achievement level. The Korean Journal of Educational Psychology, 24(1), 121-137. Retrieved from http://www.riss.kr/link?id=A77023681

Woo, H.-J., \& Park, J.-Y. (2011). A productive investigation of Korean internet studies II: A meta-analysis of internet studies in Korean communication journals during 20052010. Communication Theories, 7(1), 26-71. Retrieved from http://www.dbpia.co.kr/Article/NODE01648247

\section{ORCID}

Eun Young Chae Moon Joo Cheong http://orcid.org/0000-0002-4050-5228

http://orcid.org/0000-0001-5210-1098
Received June 30, 2016

Revision received August 16, 2016

Accepted August 20, 2016 